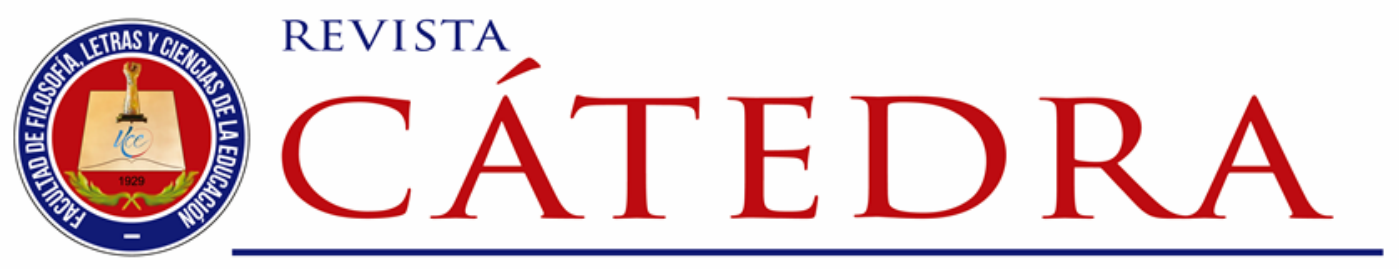

\title{
Estudio lingüístico sobre las dimensiones contextuales de la caricatura política
}

\section{Linguistic study about contextual dimensions of political caricature}

\author{
Mariela Pérez \\ Universidad Pedagógica Experimental Libertador, Barquisimeto, Venezuela \\ marielasofi@gmail.com \\ https://orcid.org/0000-0002-5583-1931
}

Yonarlli Vielma-Orellana

Universidad Técnica de Manabí, Portoviejo, Ecuador

yonarlli.vielma@utm.edu.ec

https://orcid.org/0000-0002-3462-6859

(Recibido: 27/08/2020; Aceptado: 29/08/2020; Versión final recibida: 08/09/2020)

Cita del artículo: Pérez, M. y Vielma-Orellana, Y. (2020). Estudio lingüístico sobre las dimensiones contextuales de la caricatura política. Revista Cátedra, 3(3), 33-48.

\section{Resumen}

La caricatura constituye uno de los géneros periodísticos de opinión de gran auge en las últimas décadas, en ella se conjugan multimodalmente la ironía, el humor y la sátira para analizar los hechos relevantes de un país. El análisis del discurso permite establecer una relación conjunta entre la realidad social y la cognitiva en este tipo de texto. Esta investigación se propone analizar, desde el enfoque pragmático, el discurso de la caricatura política de Eduardo Sanabria sobre la contienda electoral de 2017 en Venezuela bajo un enfoque cualitativo y diseño descriptivo-exploratorio. El análisis del discurso es la técnica empleada. El corpus estuvo conformado por cinco caricaturas publicadas en el diario El Nacional días previos a los comicios y cuyo tópico central se circunscribe a la convocatoria electoral. El análisis identificó los contextos: icónico - lingüístico, situacional y sociocultural. Los actos de habla y las figuras retóricas se identificaron como estrategias discursivas dirigidas a evidenciar la intencionalidad de una comunicación ostensiva como es la caricatura. Se tomaron los aportes de la Teoría de la Relevancia (Sperber y Wilson, 2004) y de la Teoría de los actos de habla (Austin, 2016; Searle, 2017). Se evidencia un macroacto de habla ilocutivo como es la convocatoria a votar. Se concluye que el discurso 
de las caricaturas de Sanabria expresa la crítica sobre el evento electoral a partir del juego de lo implícito, construido discursivamente entre lo icónico - lingüístico, el componente retórico y el contexto, estableciéndose una relación de complicidad con el lector.

Palabras clave

Caricatura política, contexto, pragmática, retórica, teoría de la relevancia.

\section{Abstract}

Cartoons are one of the most popular journalistic genres in recent decades, combining irony, humor and satire to analyze the relevant facts of a country. Discourse analysis allows establishing a joint relationship between social and cognitive reality in this type of text. This research aims to analyze, from a pragmatic approach, the discourse of Eduardo Sanabria's political cartoon about the 2017 electoral contest in Venezuela under a qualitative approach and descriptive-exploratory design. The analysis of the discourse is the technique used. The corpus was made up of five cartoons published in the newspaper El Nacional days before the elections and whose central topic is limited to the call for elections. The analysis identified the contexts: iconic-linguistic, situational and socio-cultural. Speech acts and rhetorical figures were identified as discursive strategies aimed at evidencing the intentionality of an ostensive communication such as caricature. The contributions of the Theory of Relevance (Sperber \& Wilson, 2004) and the Theory of Speech Acts (Austin, 2016; Searle, 2017) were taken into account. A macro-act of illocutionary speech such as the call to vote is evidenced. It is concluded that the discourse of the Sanabria cartoons expresses the criticism of the electoral event from the game of the implicit, discursively constructed between the iconic-linguistic, the rhetorical component and the context, establishing a relationship of complicity with the reader.

\section{Keywords}

Context, political caricature, pragmatics, relevance theory, rhetoric.

\section{Introducción}

La noción de discurso ha sido concebida como una práctica social e histórica en el marco de importantes procesos de socialización entre los que destaca el de los medios de comunicación. En el estudio del discurso en el ámbito mediático se aborda tanto las especificaciones de los textos y habla como la fuerza persuasiva de este en la formación de opiniones, por lo que su acceso y control se vincula a nociones de poder. En estudios sobre discurso, poder y sociedad, Van Dijk plantea que "el poder y el abuso de poder, dominación y manipulación, así como todas las formas de discurso, interacción y comunicación ilegitimas están basados en estructuras y relaciones sociales entre grupos sociales" (2016, p. 175). En el triado discurso, sociedad, cognición se establece una mediación en la que se explica la singularidad de cada discurso, dado que serán los modelos cognitivos personales y sociales, entendidos como conocimiento e ideología compartida, los que particularizan los discursos en cada situación social.

La dinámica de la sociedad moderna se encuentra signada por la presencia de los medios de comunicación, los cuales representan una especie de mediadores entre los acontecimientos sociales y los individuos. El conocimiento que obtenemos acerca de los sucesos en cada país y el mundo es obtenido mayormente por las informaciones difundidas por la prensa impresa / virtual o en redes sociales. El discurso de los medios no solo 
trasmite información, sino también expresa opiniones. Esta ubicuidad de los medios hace que sean un factor clave en la construcción de las creencias de las personas.

Entre la gama de discursos difundidos por los medios y redes sociales se encuentra el discurso humorístico en cuya esencia se encuentra la transgresión en las relaciones de poder. Autores como Calsamiglia y Tusón, coinciden en caracterizar al discurso humorístico como un juego del lenguaje en el cual su efecto es logrado a partir del no cumplimiento del proceso de comunicación convencional, seriado, alterno y organizado, siendo más bien un evento comunicativo complejo en el cual el humor se produce cuando se trasgreden las expectativas surgidas de normas y convencionalismos (1999, p. 214).

En la caricatura como género periodístico se conjuga el humor, la ironía y la sátira en su abordaje de los problemas que aquejan a cada sociedad. En el contexto venezolano Chirinos et al. refieren que:

La caricatura se ha convertido en el género periodístico que conjuga la ironía, el humor y la sátira para exponer los problemas de un país de una forma amena y diferente. En el contexto venezolano, los humoristas y caricaturistas tienen una fuente de inspiración abundante y continua (2010, p.16).

En Venezuela, las caricaturas de Eduardo Sanabria reflejan el acontecer político, económico y social del país en uno de los diarios de mayor trayectoria como es el diario El Nacional. Fueron objeto de interés de este estudio las caricaturas de Sanabria con relación al evento electoral del año 2017, donde se llevó a cabo unas elecciones de carácter regional, ocasión en la que eligieron a los Gobernadores de los 23 estados de Venezuela para el ejercicio 2018 - 2022. Este proceso eleccionario se desarrolló en una etapa caracterizada por una elevada polarización y conflictividad política.

También el ámbito social estuvo signado por la ejecución de acciones de protestas en las principales ciudades con un saldo de 142 fallecidos y 800 heridos. Esto se debió, al alzamiento en contra del modelo político y social implementado por las gestiones del presidente de turno, el cual no estaba trayendo beneficios a la población en las aéreas de salud, alimentación y educación. Aunado a ello, la coyuntura económica marcaba una dinámica de elevación de precios y acentuada escasez en los productos de primera necesidad y una afectación económica general debido a los bajos precios del barril de petróleo, el cual es la principal fuente de ingresos de la economía venezolana (Bracho, 2018, p. 538 - 539).

De tal manera que el humor y las caricaturas producidas se nutren fundamentalmente del contexto político y social, de ahí el predominio de las caricaturas políticas sobre cualquier otro tipo de humor. En este tipo específico de discurso convergen dos ámbitos: el político que signa el contenido y el periodístico que determina el espacio, la forma y el mensaje. Específicamente en el caso de la caricatura política ocurre una condensación de lo visual y lo verbal sobre asuntos cotidianos de un país, lo que sería el mundo compartido entre el autor y sus interlocutores. Sobre su función, la condensación de códigos, temas y voces persigue en lo político la descalificación de lo oficial. El humor político parte del mundo compartido y subvierte el orden (Agelvis, 2010, p. 46).

Dada la importancia de la caricatura política en la trasmisión de información y de una opinión sobre el acontecer político y social, el propósito de este artículo es analizar el discurso de las caricaturas de Eduardo Sanabria sobre la convocatoria a elecciones 
regionales en Venezuela durante el año 2017. El tema de la convocatoria a participar en dicho evento electoral es desarrollado por el autor; sin embargo, además de invitar a participar se pone en juego un dispositivo de lo implícito que evidencia una mirada particularmente crítica sobre el hecho.

A partir de estas consideraciones surgen las siguientes interrogantes: ¿cómo construye discursivamente Eduardo Sanabria la convocatoria a participar en el evento eleccionario mencionado? ¿Cuáles son las dimensiones del contexto del discurso de las caricaturas de Sanabria? ¿A través de qué estrategias discursivas se evidencia la intencionalidad del autor en las caricaturas?

El desarrollo de la investigación se orientó a través de los siguientes objetivos específicos: a) Identificar el modelo de contexto desplegado por el texto a fin de orientar la interpretación del mismo. b) Determinar los actos de habla y las figuras retóricas como estrategias discursivas dirigidas a evidenciar la intencionalidad propia de una comunicación ostensiva como es la caricatura.

Al asumir un enfoque contextual del discurso se involucran diversos aspectos de la sociedad y su cultura. El estudio del discurso "significa acercarse a la dinámica social y a las identidades, así como lograr el entendimiento sobre los diferentes grupos socioculturales en un tiempo histórico específico" (Calsamiglia y Tusón, 1999, p.16). Los usuarios del lenguaje interactúan en la construcción del significado como un asunto de sujetos socialmente organizados. Por lo tanto, el discurso no es únicamente una construcción o texto, en este van involucrados el significado, la interpretación y la comprensión del mismo.

La descripción de la situación y el contexto son componentes fundamentales del análisis pragmático para determinar la intención comunicativa que encierra el discurso o evento comunicativo (Agelvis, 2010, p. 50). En el enfoque pragmático, los elementos espaciotemporales y situacionales son interpretados en el marco sociocultural de las personas, quienes, al mismo tiempo, integran la información en su mente gracias a los procesos cognitivos. En este sentido, el estudio pragmático-discursivo debe considerar el análisis del contexto, entendido este como el mundo del autor y el mundo de quien interpreta el texto (Calsamiglia y Tusón, 1999, p. 102). Particularmente, en la caricatura, la imagen y el texto breve que generalmente se adjunta, constituyen las claves visuales y verbales escogidas por el autor para desplegar un proceso de interpretación basado en lo que el lector interpreta y en cuya génesis se encuentran los factores contextuales.

Pero el discurso también es una actividad cognitiva, es una práctica que cubre un recorrido en dos sentidos, interacción verbal y suceso de comunicación. Sus "significados, inferencias e intenciones, así como otras propiedades y procesos de la mente son intrínsecos al texto" (Van Dijk, 1999, p. 246-247).

No obstante, la aproximación cognitiva no concibe al significado como un valor inmanente al mismo, sino que este es atribuido por los usuarios y sus procesos mentales. Así lo expresa Calsamiglia y Tusón:

Sin embargo, el sentido - o significado pragmático-discursivo- resulta de la interdependencia de los factores contextuales y las formas lingüísticas; exige de quien lo interpreta, sus conocimientos previos y compartidos, sus intenciones, todo aquello que se activa en el intercambio comunicativo, así como el resto de dimensiones del contexto empírico en que se produce (1999, p. 185).

Licencia Creative Commons Atribución 4.0 Internacional (CC BY 4.0)

Revista Cátedra, 3(3), pp. 33-48, septiembre-diciembre 2020. e-ISSN:2631-2875

https://doi.org/10.29166/catedra.v3i3.2202 
El discurso y sus procesos mentales se insertan en la dinámica social. Desde esta visión, el proceso de interpretación de un enunciado conlleva a identificar lo dicho explícitamente por el emisor, lo que ello implica, la intención del emisor y del contexto en el que pretende que se procese su enunciado.

El lenguaje es acción según la teoría de los actos de habla desarrollada por (Austin, 2016; Searle, 2017). El hablar es hacer, de manera que al emitirse un enunciado este posee un significado explícito, una dimensión intencional y una dimensión que repercute en la audiencia. Al respecto existen "consecuencias o efectos que tales actos tienen sobre las acciones, pensamientos o creencias de los oyentes" (Searle, 1994, p.34).

La noción del lenguaje como acción concibe que en todo acto comunicativo existe un acto intencional, producido para que el interpretante realice alguna acción, creer algo de lo dicho, actuar acorde a alguna convención, en fin, actuar en consecuencia. En este sentido, el enunciador "puede querer decir más de lo que efectivamente dice, pero a él le es siempre posible en principio decir exactamente lo quiere decir" (Searle, 1994, p.27).

Por otro lado, una aproximación discursiva al tema del significado tiene que plantear necesariamente la diferencia entre significado explícito y significado implícito. En este aspecto del análisis es necesario considerar el uso de las figuras retóricas como estrategias discursivas o transgresiones del lenguaje empleadas con el fin de hacer relevante determinada información. En la teoría de la relevancia se estudia el significado implícito y los fenómenos ostensivos. Estos últimos ocurren cuando el hablante o autor de un discurso contribuye significativamente a que se reconozca su intención comunicativa (Sperber y Wilson, 2004, p. 241). Dentro de la llamada comunicación ostensiva se encuentra una forma de análisis de unidades mixtas (texto e imagen) ya que las caricaturas funcionan como textos ostensivos cuyo fin es provocar la atención pública.

En esta investigación la caricatura es concebida como un discurso integrado por tres componentes, los cuales son los tipos de contextos que se denotan para establecer el análisis según lo tipifica Reyes:
a) contexto lingüístico o co-texto, material lingüístico que precede y sigue al enunciado. b) contexto situacional o dimensión espacio-temporal del enunciado. c) contexto sociocultural que comprende las ideas, las escalas de valores, y los conocimientos culturales de todo tipo compartidos por los interlocutores (2007, p. 19).

La perspectiva pragmática conduce a la noción de texto caricaturesco como un evento comunicativo, en el cual se persigue el estudio del uso del lenguaje en contexto y como la construcción de una mirada particular sobre un evento específico. Su estudio persigue identificar las intenciones del autor, así como caracterizar el contexto probable en el que se propone se realice la interpretación de la caricatura.

El artículo presenta cuatro secciones. La primera sección se esboza el desarrollo del estudio describiendo el contexto del análisis. En la segunda sección se encuentra los materiales y métodos donde se indican los procedimientos inherentes a la investigación de corte cualitativo y según las técnicas del Análisis del Discurso. En la tercera sección se ubica la parte de los resultados, aquí se expresan los productos del procesamiento de la información logrado a través de las matrices diseñadas y analizadas de manera integrada. Finalmente, en la cuarta sección se sitúan las conclusiones, se reflexiona sobre los resultados del análisis del corpus a la luz de la visión del discurso de la caricatura política en el ámbito social. 


\section{Materiales y métodos}

La investigación se inscribe en el enfoque de investigación cualitativo, el cual plantea "el estudio de casos específicos sin necesidad de generalizar en grandes cantidades de datos, buscando analizar y describir los fenómenos sociales a partir de sus rasgos determinantes" (Bonilla y Rodríguez, 2005, p.110).

El tipo de investigación es de carácter descriptivo-exploratorio, cuyos estudios descriptivos muestran las propiedades, características y perfiles de personas o cualquier otro fenómeno sometido a análisis, con la finalidad de evaluar sus dimensiones o componentes (Hernández et al., 2014).

El procedimiento para llevar a cabo esta investigación fueron los siguientes:

1. Arqueo bibliográfico sobre el tema a investigar: Se realizó una investigación exhaustiva para ubicar los principales modelos teóricos relacionados a la pragmática, así como también aquellos vinculados a la caricatura política.

2. Búsqueda y selección intencional del corpus: El corpus estuvo conformado por cinco caricaturas de Eduardo Sanabria publicadas en el diario El Nacional y cuyo tópico central se circunscribe al evento electoral convocado en Venezuela el 15 de octubre de 2017. La selección fue intencional y obedece al interés por estudiar la interacción pragmática en las caricaturas de Eduardo Sanabria referidas a la convocatoria a participar en las elecciones regionales. Las mismas fueron numeradas progresivamente de acuerdo a las fechas de publicación y corresponden a los días previos a los comicios.

3. Elaboración de las matrices: Se diseñó una matriz denominada modelo de contexto en la caricatura, orientada a identificar el contexto icónico- lingüístico, el situacional y el contexto sociocultural de la comunicación ostensiva como dimensiones participantes en la construcción del significado. Y otra matriz llamada perspectiva pragmática-retórica de la caricatura siguiendo los aportes de (Calsamiglia y Tusón, 1999) para identificar los actos del habla y las figuras retóricas.

4. Segmentación de las unidades de análisis en las matrices: La unidad básica de análisis fue el enunciado, definido este como toda producción lingüística con sentido que tenga una intención comunicativa. En este sentido "en cualquier caso, producir un enunciado implica realizar un tipo de acción: un acto de habla" (Escandell, 2014, p.166).

5. Análisis de las caricaturas: En primera instancia se procedió a identificar el modelo de contexto desplegado por el texto a fin de orientar la interpretación del mismo. La acción de identificación abarcó tres niveles. En el contexto icónico lingüístico fueron reconocidos tanto las imágenes de cada caricatura como el texto en su manifestación verbal apelando al conocimiento enciclopédico del lector. El contexto situacional tuvo que ver con las condiciones de la publicación y el contexto sociocultural involucró el conocimiento compartido acerca del tema y hechos relevantes asociados al mismo, en la actualidad y épocas anteriores en Venezuela. En segunda instancia se determinaron los actos de habla y las figuras retóricas como estrategias discursivas. En este aspecto, la unidad de análisis fundamental fue el enunciado y a partir de estos fueron identificadas las acciones de habla y las figuras retóricas. El análisis pragmático se completa al integrar dinámicamente tanto el modelo de contexto como la perspectiva pragmático - retórica a fin de evidenciar el juego interaccional del contexto con el texto en la construcción de un discurso y de una perspectiva especifica del autor. 
Para poder realizar el análisis se recopilaron una serie de caricaturas seleccionadas intencionalmente en atención a conformar el corpus de Eduardo Sanabria en lo referente a la convocatoria a participar en las elecciones regionales del 2017 en Venezuela.

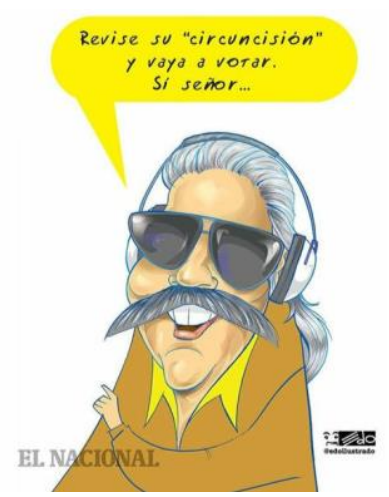

Figura 1 Caricatura del personaje "El Chunior", locutor venezolano, codificación C1 en esta investigación. Fuente: (Sanabria, 2017, 8 de octubre).

La caricatura desde el plano icónico representa un personaje popular humorístico venezolano apodado "El chunior". En el plano verbal se presenta una oración asertiva y una exclamativa.

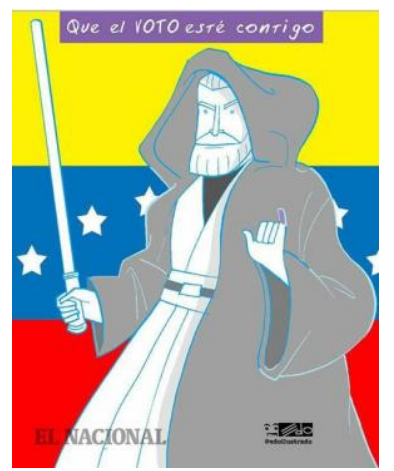

Figura 2 Caricatura del maestro Jedi Obi-Wan Kenobi personaje de la película "La guerra de las galaxias", codificación C2 en esta investigación. Fuente: (Sanabria, 2017, 9 de octubre).

La C2 está compuesta por un solo personaje de la película mencionada y de fondo la bandera nacional venezolana. En el plano verbal se tiene una oración desiderativa.

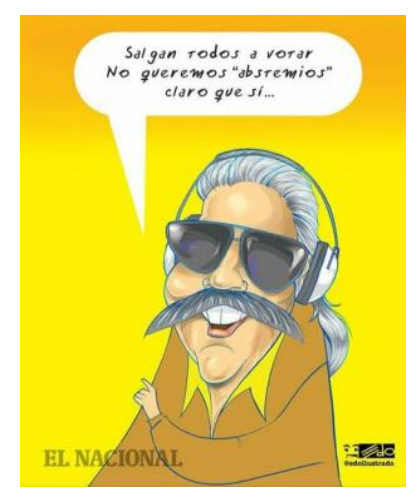


Figura 3 Caricatura del personaje “El Chunior”, locutor venezolano, codificación C3 en esta investigación. Fuente: (Sanabria, 2017, 11 de octubre).

En la C3 se repite la estructura narrativa única. Nuevamente el personaje es el llamado "Chunior". El plano verbal se encuentra caracterizado por oraciones exhortativas y desiderativas.

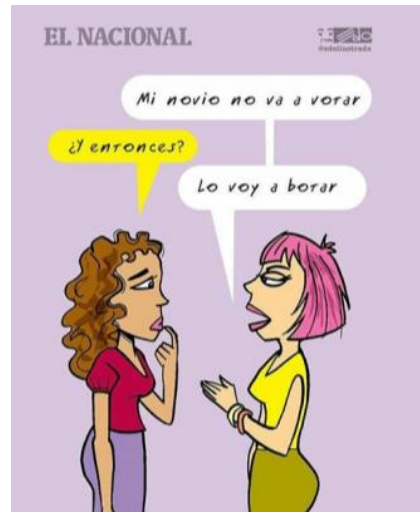

Figura 4 Caricatura de un par de mujeres conversando, codificación C4 en esta investigación. Fuente: (Sanabria, 2017, 12 de octubre).

En el plano icónico, C4 representa dos mujeres jóvenes charlando. En el plano verbal se desarrolla brevemente un diálogo caracterizado por oraciones enunciativas e interrogativas.

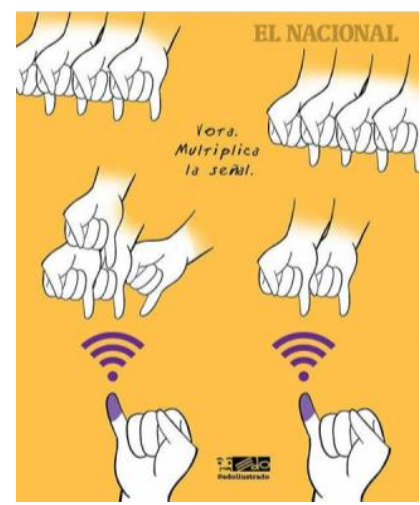

Figura 5 Caricatura de dos meñiques con tintura electoral, codificación C5 en esta investigación. Fuente: (Sanabria, 2017, 13 de octubre).

El plano icónico revela un par de manos con el meñique tinturado y una serie de manos receptivas ante la señal de voto ejercido. El plano lingüístico está conformado por la exhortación.

\section{Resultados}

Una vez seleccionado el corpus y diseñadas las matrices de procesamiento de los textos, se desarrolló el análisis de las caricaturas. Tomando en cuenta que los enunciados segmentados en las matrices de análisis constituyeron la clave fundamental. En primer lugar, porque representa el punto verbal central para que el lector realice la tarea de

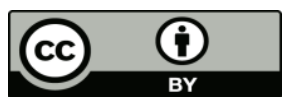


interpretación, es decir, para que identifique lo que la caricatura dice o implica. Y en segundo lugar, el contexto de interpretación en el que el caricaturista espera que se procese su caricatura.

\begin{tabular}{ccccc}
\hline \multicolumn{5}{c}{ Contexto icónico- lingüístico } \\
\hline C1 & C2 & C3 & C5 & \\
& & & & \\
$08 / 10 / 17$ & $09 / 10 / 17$ & $11 / 10 / 17$ & $12 / 10 / 17$ & $13 / 10 / 17$ \\
\hline
\end{tabular}

\section{Contexto situacional}

Serie de caricaturas cuyo autor es Eduardo Sanabria publicadas en el diario El Nacional, periódico venezolano, fundado en la ciudad de Caracas el 3 de agosto de 1943 de circulación nacional y larga tradición en el país. Las caricaturas fueron publicadas en el lapso comprendido entre el 08 al 13 de octubre de 2017 en días previos a la realización de los comicios.

\section{Contexto sociocultural}

El 15 de octubre de 2017 se realizaron las elecciones regionales en Venezuela, evento en el que se eligieron los gobernadores de los 23 estados del país para el ejercicio 2018 2022. Este evento estuvo caracterizado por una alta polarización y conflictividad y fuertes protestas durante los cuatro meses previos a los comicios. Por ello, oposición y oficialismo hicieron reiterados llamados a votar a fin de evitar la abstención característica de las elecciones regionales. Por una parte, el gobierno invitaba a participar en la "fiesta electoral" para garantizar la paz; por otro lado, la oposición denunciaba la reubicación a menos de 72 horas de la elección de más de 250 centros de votación, muchos de ellos en zonas tradicionalmente opositoras; la trasmisión por medios estatales de propaganda electoral oficialista prohibidos por la ley con anterioridad y la presencia de "colectivos" adeptos al oficialismo en colegios electorales opositores.

Cuadro 1. Modelo de contexto en la caricatura

Modelo de contexto: El corpus de caricaturas seleccionadas alude al evento electoral antes referido. El criterio de selección intencional correspondió al interés en indagar en la convocatoria a participar, en la elección tal como es representada por el autor, Eduardo Sanabria. El contexto icónico - lingüístico corresponde tanto a las imágenes como a la serie de enunciados de cada caricatura. Cada una está conformada por un cuadro dentro del cual aparece la imagen de los personajes y poco texto. Los dibujos remiten a personajes reales presentados con rasgos prominentes; los textos refieren discursos o puntos de vista de dichos personajes o seres reales caricaturizados.

El contexto del corpus coincide con la definición de Agelvis (2010) quien establece que, tanto en el lenguaje icónico como en el verbal está presente la sátira o crítica llena de humor o ironía con el propósito de persuadir. Las imágenes representan personajes exagerados cuyo significado cobra relevancia a la luz del contexto. Entre los personajes representados se encuentra "El Chunior" (C1, C3) quien es una de las caracterizaciones más famosas del actor humorístico Emilio Lovera siendo "El Chunior" un alegre locutor que siempre hace gala de una falsa sabiduría y cultura general. También se visualiza al Maestro Jedi Obi-Wan Kenobi (C2) personaje de la película La Guerra de las Galaxias. Un Par de mujeres conversando (C4) y dedos meñiques con tintura electoral (C5). En relación a los textos, los 
mismos son muy breves, en los cuales no hubo la posibilidad de establecer relaciones gramaticales anafóricas.

El contexto situacional está caracterizado por las condiciones propias de una publicación mediática. El autor, Eduardo Sanabria, es un caricaturista cuya obra incluye el dibujo humorístico infantil, publicitario y el retrato de personalidades, sin embargo, es la caricatura política lo que lo lleva a la fama. El diario El Nacional representa un medio de comunicación de larga trayectoria en el país.

El contexto sociocultural correspondiente al lapso de tiempo en el que fueron publicadas las caricaturas se relaciona directamente con la invitación a participar en los comicios regionales. El llamado a participación fue realizado por ambos polos de la elección. El lado oficial, cuya cara visible era el gobierno de turno, realizó la convocatoria bajo la premisa de que la participación en la "fiesta" electoral haría posible la paz, en alusión a los cuatro meses de protestas que antecedieron al desarrollo de las elecciones regionales.

En el marco previo a la realización del evento ocurrieron hechos puntuales vinculados a las condiciones de la participación, el Consejo Nacional Electoral abruptamente cambia las circunscripciones electorales, esto originó que gran parte de la población fue reasignada a centros de votación diferentes, en ocasiones, lejanos de su domicilio. Este hecho fue denunciado por la oposición al igual que las violaciones a la norma electoral por parte del

\begin{tabular}{|c|c|c|c|}
\hline Caricatura & Acto locutivo & Tipo de acto ilocutivo & Figuras retóricas \\
\hline \multirow[b]{2}{*}{ C1 } & Revise su "circuncisión" & Directivo & Permutación \\
\hline & Y vaya a votar & Directivo & \\
\hline $\mathrm{C} 2$ & Que el voto esté contigo & Expresivo & Figura polisémica \\
\hline \multirow{3}{*}{ C3 } & Salgan todos a votar & Directivo & \\
\hline & No queremos "abstemios" & Expresivo & Metáfora \\
\hline & Claro que sí & Expresivo & \multirow{4}{*}{ Aliteración } \\
\hline \multirow[b]{3}{*}{$\mathrm{C} 4$} & Mi novio no va a votar & Asertivo & \\
\hline & ¿y entonces? & Directivo & \\
\hline & Lo voy a votar & Compromisorio & \\
\hline \multirow{2}{*}{$\mathrm{C} 5$} & Vota & Directivo & \\
\hline & Multiplica la señal & Directivo & Metáfora \\
\hline
\end{tabular}

sector oficialista al difundir propaganda electoral en medios de comunicación del Estado, así como la presencia organizada de colectivos políticos afectos al gobierno en los centros de votación y en los actos de la oposición. Estos colectivos practicaban la confrontación violenta lo que generaba temor en la población (Bracho, 2018).

Cuadro 2. Perspectiva pragmática- retórica de la caricatura 
La idea de que al emitir un enunciado se realiza una acción por medio de las palabras es el fundamento de la teoría de los actos de habla. Los actos ilocutivos expresan una fuerza en virtud de la cual la enunciación alude a tipo de acciones particulares. De ahí que Searle (1994) estipuló cinco tipos de actos ilocutivos: asertivos, directivos, compromisorios, expresivos y declarativos.

El predominio de los actos de habla ilocutivos de tipo directivos y expresivos resultan coherentes con un tipo de comunicación ostensiva como es la caricatura. Si los actos directivos persiguen que se realice una acción, los actos expresivos sirven para manifestar el estado psicológico sobre lo que se siente o piensa el hablante, de acuerdo con el contenido proposicional.

Por otro lado, las figuras retóricas identificadas como estrategias discursivas de Eduardo Sanabria pertenecen a dos grupos, de acuerdo a los rasgos lingüísticos vinculados a esta investigación son:

1) Figuras de palabras, aquellas logradas a través de procedimientos aplicados a nivel fónico. Gráfico, morfológico o léxico de las palabras. Calsamiglia y Tusón (1999): Permutación: "Revise su circuncisión" (C1) donde ocurre la permutación o cambio de una palabra esperada por otra con sonidos parecidos y significado diferente. Aliteración: Votar - Botar donde se repite el mismo sonido en palabras con significados diferentes (C4).

2) Figuras de sentido, aquellas figuras producidas a través de procesos de significación por relaciones de analogía u otros tipos de relación: Metáfora: "No queremos abstemios" (C3) y "Multiplica la señal" (C5) y Enunciado polisémico cuyo sentido es contextual en "Que el voto te acompañe" (C2).

\section{Discusión}

La teoría de la Relevancia coincide con otras corrientes lingüísticas en la idea de que no hay una correspondencia única entre las oraciones y sus contenidos semánticos y su interpretación según (Sperber y Wilson, 2004). Particularmente, en el tipo de comunicación ostensiva, en la que el emisor activamente llama la atención del destinatario, los significados expresados en el nivel lingüístico superan lo literal. La contextualización de las caricaturas del corpus son premisas obtenidas de los mecanismos deductivos inherentes a la memoria enciclopédica y a la decodificación ícono - lingüística.

La caricatura despliega claves visuales y textuales que activan procesos inferenciales a fin de identificar lo comunicado por el autor explicita e implícitamente. De tal manera que la interpretación de los enunciados icónicos-lingüísticos cobra sentido en la visión macro que incluye al contexto situacional y sociocultural.

Si bien el propósito general explícito de las caricaturas se encuentra inserto en la convocatoria pública a participar en los comicios regionales de 2017. A la luz del análisis contextual puede colegirse un uso interpretativo de las representaciones mentales desplegadas en la serie de actos ilocutivos identificados en las caricaturas.

El predominio de actos de habla directivos describe un estado de cosas exigidos desde el punto de vista del hablante o autor. Participar, votar, elegir, acudir a votar indica acciones que el hablante considera deseables desde su punto de vista. De igual forma los actos ilocutivos de tipo expresivo representan un estado de cosas que existen en el pensamiento y emociones del hablante. De manera que en el marco situacional y sociocultural el corpus 
atiende a una intencionalidad manifiesta de apoyo a la convocatoria. Es decir, se suman al llamado de los medios de comunicación a participar en un evento electoral del país.

No obstante, las figuras retóricas permiten construir un significado implícito en el cual se refuerza el uso interpretativo. A la intencionalidad de los actos de habla se suma la actitud del autor hacia lo comunicado. De esta manera las estrategias retóricas permiten llamar la atención del interlocutor sobre otros aspectos o hechos que no están explícitos en el enunciado, pero con los que el interlocutor puede establecer relación debido a que forman parte del contexto sociocultural compartido.

En C1 el acto ilocutivo directivo solicita la acción de votar, sin embargo, la figura de palabras o permutación empleada en el enunciado: "Revise su circuncisión" sorprende al lector al no utilizar la palabra esperada como es "circunscripción", lo cual no impide su comprensión ya que en este mensaje el contexto social aporta la información fática al lector como es la acción tomada por el CNE venezolano de cambiar las circunscripciones tres días antes de los comicios. El juego de palabras y el personaje caricaturesco tan conocido como "El chunior" logran, desde el humor, advertir al lector sobre ese posible obstáculo en el ejercicio del sufragio. Las figuras de palabras también se encuentran en C4 con la figura de aliteración o juego fónico entre "votar" y "botar", caricatura en la que se interpreta como acción negativa la no participación.

En el uso figurativo del lenguaje cabe especial mención la construcción cognitiva representada en las metáforas o figuras de sentido. En C3 el enunciado "No queremos abstemios" expresado por el personaje "El chunior" establece una relación analógica entre el evento electoral y una celebración. Esta analogía de la metáfora tiene su antecedente contextual en el habla cotidiana venezolana en la que se reconoce ampliamente la imagen a través de la cual el Gobierno de la nación ha denominado por mucho tiempo a las elecciones como la "fiesta electoral" y que ya forma parte del imaginario compartido por la mayoría de los venezolanos.

Estos enunciados han sido considerados como enunciados de "eco" dado que en ellos se alude a algo anteriormente enunciado por otro hablante (Sperber y Wilson, 2004). De manera que, inscrita en el ámbito de la celebración, la expresión "no queremos abstemios" alude a la perspectiva opositora que llama a participar masivamente ya que la abstención favorecería al oficialismo.

Las metáforas proyectan relaciones de analogía entre ámbitos normalmente distintos. En la proyección entre estos dominios se construye un punto de vista subjetivo puesto que incorporan el punto de vista del emisor (Escandell, 2014). El enunciado de C5 "multiplica la señal", en este caso ilustrado con varias manos con el dedo meñique tinturado como muestra de haber ejercido el voto, refiere metafóricamente a un evento comunicativo vinculado a la realización de los comicios. El uso indiscriminado de los medios de comunicación por parte del oficialismo, es un ejemplo de ello; así como el cambio de circunscripciones inesperadamente lo que debilitaba el derecho de un sector de los electores a estar informados, por lo que debían propagar la información.

El contexto sociocultural compartido abarca también frases, expresiones, refranes que se han incorporado al acervo cultural, y es un conocimiento basado en experiencias cuya expresión metafórica es incorporada a la vida cotidiana. Tal es el caso en C2 y el enunciado "que el voto esté contigo" que juega con el personaje de la caricatura, el Maestro Jedi Obi Wan quien en la película Stars Wars pronuncia la famosa frase "que la fuerza esté contigo". La variación de la frase parte de lo conocido y amplifica el mensaje. El enunciado es

Licencia Creative Commons Atribución 4.0 Internacional (CC BY 4.0)

Revista Cátedra, 3(3), pp. 33-48, septiembre-diciembre 2020. e-ISSN:2631-2875

https://doi.org/10.29166/catedra.v3i3.2202 
susceptible de ser interpretado de varias formas. Inicialmente puede interpretarse que se desea que la participación sea realizada; sin embargo, también el interlocutor puede reconocer la famosa frase y además conocer que la misma se pronuncia como deseo de buena fortuna antes de un combate. Por tanto, se puede inferirse que se le desea la mayor de las suertes ante una circunstancia posiblemente adversa para la participación electoral ante hechos como los ya nombrados y la posibilidad de violencia en el desarrollo del evento.

El discurso humorístico pone en evidencia el juego contextual generado a partir de las estrategias discursivas que lo conforman, en ellas, lo literal es solo una parte de lo comunicado. Visto como práctica social, el discurso humorístico parte de una intencionalidad explicita y se inscribe en el marco de convenciones y propósitos compartidos por la sociedad en la que circula. En este sentido, en las caricaturas políticas analizadas se evidencia un macroacto de habla ilocutivo como es la convocatoria a votar, de manera que la intencionalidad del autor participa del contexto situacional, como es el de la comunicación social.

No obstante, el juego de la construcción del sentido cobra fuerza ilocucionaria al analizar los actos de habla en el contexto sociocultural y en su interacción retórica. De la misma forma que un enunciado es susceptible de presentar un abanico de interpretaciones según su morfología, sintaxis o semántica, igualmente la caricatura, analizada contextualmente, asoma varias opciones de interpretación. Esto obedece a las posibilidades diferentes de combinación entre los enunciados lingüísticos y la representación iconográfica.

La convocatoria a participar con el voto conlleva implícitamente una visión, que, al ser humorística, insinúa la crítica social. El juego irónico del humor presente a través de las figuras retóricas estructura lo implícito. En estos mensajes, cada lector procesará de acuerdo al acceso que dispone del contexto sociocultural. Está claro que los contextos varían para cada lector y desplegará contextos de interpretación específicos para su relevancia.

\section{Conclusiones}

En el estudio del humor y sus configuraciones discursivas es indiscutible que no hay sentido en el mensaje si no hay un conocimiento socioculturalmente compartido. Investigaciones coinciden en resaltar la perspectiva discursiva como una opción "integradora, coherente y de preferencia multidisciplinar" (Morales y Samper, 2017, p. 83). Con ello se reivindica la vitalidad del lenguaje y la necesidad emergente siempre de abordarlo sin enfoques reduccionistas.

En el caso de la caricatura política, el manejo del contexto por parte del lector es un factor clave en la tarea interpretativa. La construcción discursiva del humor en el corpus analizado obedece a una adecuación contextual entre el texto, el autor y el lector que permite una especie de complicidad comunicativa.

A través del discurso humorístico, la caricatura política de Eduardo Sanabria devela las circunstancias adversas a la celebración electoral realizada en Venezuela en 2017. Así visto, existe en el mensaje un mapa de interpretación cuyo recorrido es ejecutado por un juego estratégico de votar para contrarrestar la abstención favorecedora al gobierno, y el votar como una acción heroica en una guerra entre la luz y la oscuridad o la acción del sufragio como señal democrática que se multiplica en cada ciudadano.

Todas estas posibles interpretaciones están enmarcadas en una actitud del autor, la cual es caracterizada por una posición democrática y de oposición ante la opción 
progubernamental. El acervo de creencias compartidas y el juego interpretativo conforman el universo pragmático del discurso de Eduardo Sanabria.

Estudios recientes en el área muestran como la potencialidad discursiva del humor político de la caricatura ha convertido a la misma en un corpus atractivo para aquellas investigaciones cualitativas dirigidas a ahondar en las representaciones sociales y en las construcciones semióticas y discursivas de la ideología en sociedades, cada día más signadas por la información y las matrices de opinión difundidas por los medios de comunicación (Prada et al., 2018).

\section{Bibliografía}

Agelvis, V. (2010). Zapata y la caricatura. Anuario Grhial, 4 (4), 43-62. De http://www.saber.ula.ve/handle/123456789/32815

Austin, J (2016) Cómo hacer cosas con palabras. España: Paidós Ibérica.

Bracho, Ángel (2018). Tratamiento sobre política y economía en la prensa nacional tras el 15 octubre de 2017. Análisis de contenido. Telos, 20 (3), http://www.redalyc.org/articulo.oa?id=993570020010

Bonilla-Castro, E. y Rodríguez Sehk, P. (2005). Más allá de los dilemas de los métodos. La investigación en Ciencias Sociales. Grupo editoral Norma: Bogotá-Colombia.

Calsamiglia, H. y Tusón, A. (1999). Las cosas del Decir. Barcelona: Editorial Ariel Lingüística.

Chirinos, A, Franco, A y León, F (2010). Análisis semio-lingüístico de las caricaturas de Pedro León Zapata. Revista de Artes y Humanidades Única, 1 (1), 15-43.

Escandell, M.V. (2014). La comunicación. Lengua, cognición y sociedad. Madrid: Akal.

Hernández, R., Fernández, C., y Baptista, P. (2014). Metodología de la investigación. México: Mc. Graw Hill.

Morales, E. \& Samper, J. (2017). Abordaje discursivo de una caricatura política. Amauta, 15(39), 71-83. http://doi.org/10.15648/am.30.2017.6

Prada, J; Ramirez, J y Pinzón, D (2018). Articulación de la caricatura política como fuente para la investigación social en Colombia: estado del arte y perspectivas a comienzos del siglo XXI. Reflexión Política, vol. 20, núm. 40. https://dialnet.unirioja.es/servlet/articulo? codigo=6837419

Reyes, G. (2007). El abecé de la Pragmática. Arco Libros

Sanabria, E. (13 de octubre de 2017). Vota. Multiplica la señal. El Nacional. Recuperado de https://www.instagram.com/p/BaMM0RqAbL4/

Sanabria, E. (12 de octubre de 2017). Mi novio no va a votar ¿y entonces? Lo voy a votar. El Nacional. Recuperado de https://www.instagram.com/p/BaloVryAxgW/

Sanabria, E. (11 de octubre de 2017). Salgan todos a votar. No queremos "Abstemios" claro que si... . El Nacional. Recuperado de https://www.instagram.com/p/BaHGJjQAbKe/ 
Sanabria, E. (9 de octubre de 2017). Que el voto esté contigo. El Nacional. Recuperado de https://www.instagram.com/p/BaCMU4XAw-h/

Sanabria, E. (8 de octubre de 2017). Revise su “circuncisión” y vaya a votar. Si señor... El Nacional. Recuperado de https://www.instagram.com/p/BaCMU4XAw-h/

Searle, J. (2017). Actos de habla: Madrid: Cátedra.

Searle, J. (1994). Actos del habla: Ensayo de filosofía del lenguaje. Planeta-Agostini: Barcelona.

Sperber, D. y Wilson, D. (2004). Teoría de la Relevancia. Revista de Investigación Lingüística, 7, 233-283. De http://revistas.um.es/ril/article/view/6691

Van Dijk, T. (1999). Ideología, una aproximación multidisciplinaria. Gedisa: Barcelona.

Van Dijk, T. (2016). Estudios críticos del Discurso: un enfoque sociocognitivo. En Discurso y sociedad. Vol.10 (1) pp. $137-162$ 


\section{Autores}

MARIELA PÉREZ. Magister en Lingüística, 2002. Universidad Pedagógica Experimental Libertador (UPEL-IPB), Venezuela. Licenciada en Letras. Mención Lenguas y Literatura Clásicas, 1996. Universidad de Los Andes, Venezuela.

Actualmente doctorante en Cultura Latinoamericana. Tesis en curso. Coordinadora de la Maestría en Lingüística. UPEL-IPB.

Docente en las cátedras de Introducción al Estudio de la Lengua, Lengua Española y Comprensión y Producción de Textos en pregrado. Docente cátedra Teoría Lingüística. Análisis del Discurso y Seminario de Lectura y Escritura (Maestría en Lingüística UPELIPB.) Docente cátedra Tipología del Texto Literario. (Maestría Literatura Latinoamericana. UPEL-IPB.)

YONARLLI VIELMA-ORELLANA. Licenciado en Educación Mención Francés, 2015. Universidad de Carabobo, Venezuela. Miembro de la Asociación Venezolana de Profesores de Francés y de la Asociación Venezolana para la Enseñanza del Español como Lengua Extranjera.

Actualmente maestrante en lingüística Universidad Pedagógica Experimental Libertador (UPEL-IPB), Venezuela, por sustentar trabajo de grado. Docente de francés Universidad Técnica de Manabí, Portoviejo, Ecuador. 